\title{
Relationship marketing in service oriented companies: Retail pharmacy case study
}

ISSN 1857-9973

UDC 658.87:615.1]:303.62(497.7)

\section{Dushko Kocev ${ }^{1}$}

1University Goce Delcev Stip, Faculty of Economics, PhD student, dusko.kocev@t.mk

\begin{abstract}
Marketing is a moral responsibility of every modern company. All successful companies have to be marketing oriented. Marketing concept is based on the idea that customers and satisfaction of their needs and wants are always in focus of the companies, as most appropriate manner for increasing their profitability. Small companies are forced to be marketing oriented, also. Small companies have generally employed intuitions rather than marketing research techniques in their attempts to maximize customer satisfaction. Managers of small firms usually are focused on the fact that products and services they provide are those factors that will satisfy and retain the consumers. Most of small firm managers are not concerned with potential feedback from consumers. Relationship marketing as valuable tool for attracting and retaining consumers in small service oriented companies is defined in the study. How relationship marketing works in practice is shown through case study conducted in local retail pharmacy. Challenging situation for the pharmacy is to discover how to increase the profit when work with uniform prices of drugs. The research process conducted in the study has to provide insights into relationship marketing based on the patient's behavior and patients buying decision making. Cognition of these two aspects would serve as good basis for developing further marketing actions for retaining the existing and attracting new patients as strategy for increasing the profit.
\end{abstract}

Key words: Marketing, Pharmaceutical Marketing, Relationship Marketing, SMEs marketing,

\section{Introduction}

In today's competitive environment and specific time for working and growing business it is too risky, not to know the functioning of basic marketing concepts. Every successful company, even it is a small, has to be marketing oriented company. In marketing oriented companies, the consumers and satisfying their needs and wants are always in focus. According (Kotler et al. 2009), instead of a product-centered and make-and-sell philosophy, business shifted to a customer-centered, sense-and-respond philosophy. Kotler claims that the marketing task is not to find the right customers for your products or services, but to design the right services and products for your customers.

Through the science practice there are many attempts for defining marketing concept with one sublimated definition, but the marketing is something that cannot be explained in several words. The marketing concept is based on one simple idea, but at the same time the idea is most 
important and difficult for the companies to achieve it. Marketing concept is based on the idea that customers and satisfaction of their needs and wants are always in focus of the companies, as most appropriate manner for increasing their profitability.

The whole company, from the top management to the lowest levels, must adopt this marketing philosophy. Nowadays companies are marketing oriented companies, the marketing sector is always is in the middle of attention and decisions from the marketing sector circulate among whole organizations and represent most important ways of action.

Marketing and marketing departments are most important elements in the organizational structure of the companies and factors which provides business success. In today's highly competitive environment the financial success often depend from the marketing ability of the company. Marketing represent organized effort for acquiring customers, maintaining and growing them for organizational profitability. There is a mass of definitions for the marketing and every definition has own specific scientific value.

As (Levinson 2007) noted: "Marketing is not an event, but a process...It has a beginning, middle, but never an end, for it is a process. You improve it, perfect it, change it, even pause it. But you never stop it completely". The marketing philosophy must to be adopted by the whole company, from the top management to the lowest levels and across all departments of the organizations. The customers' needs and wants and their satisfaction should always be in every managers and employees mind. Marketing is about identifying and meeting human and social needs. According (Gummesson 2007), marketing is the process of meeting needs profitably. This is called balanced centricity - which is a focus on a customer, but also on the company and its objectives. Peter (Drucker 1973), a leading management theorist, describes the process of marketing as follow: "The aim of marketing is to know and understand the customer so well that the product or service fits him/her and sells itself. Ideally, marketing should result in a customer who is ready to buy. All that should be needed then is to make the product or service available. Marketing practice can be viewed from many perspectives. Marketing practice can be viewed by managing and analyzing the elements of the marketing mix. The most represented division of the marketing mix is that by (McCarthy and Perreault 2002) who classifies marketing activities as marketing mix tools into four categories, called 4Ps of marketing: product, price, place, promotion with all their under elements. The 4Ps of the marketing mix represent the company's views of the marketing tools available for influencing buyers. Knowing the marketing mix tools, marketing managers have available a variety of short and long term marketing strategies, to perform on the target market. The Marketing management process represents a sub technique of the whole marketing process. According (Kotler et. al 2009), marketing management is the art and science of choosing target markets and getting, keeping and increasing number of customers through creating, managing, communicating and delivering superior customer value. One of the most valuable tools in the marketing management is marketing research process which helps to identify customer's needs and wants. It helps to improve management decisions by providing relevant, accurate and timely information.

The scope of the study is to conduct marketing research process in micro company to get insights for the challenging situation that the company is faced with. The pharmacies and possible actions for increasing their profits when working with uniform prices of drugs will be subject of observation in the study. The marketing research will be examined in practice for gaining information about the relationship marketing focused on consumer/patient behavior and consumer behavior decision making. Knowing the results from the research about the patient's behavior, it will be a good basis for providing further marketing strategies for the pharmacy for increasing their profit. 


\section{Retail pharmacy marketing approaches}

Independent retail pharmacy or community pharmacy represents a type of micro enterprise, significantly influenced by its professional role. Retail pharmacy is a profession which trades. While pharmacy is a profession, (Kayne 2005) contends that it is probably more overt in portraying the marriage of profession and business than most other professions. While pharmacy today is noted for providing many other services other than the dispensing of medicines it is suggested that not only are professionalism and business compatible, they are inextricably and synergistically linked. Perhaps going further, (Desselle \& Zgarrick, 2005) suggests that good business and good patient care are almost entirely mutually dependent.

Research has found that marketing in the independent retail pharmacies is strongly influenced by resource constraints and by the attitudes, skills and knowledge of the owner/manager. Researchers have argued that marketing practice in SMEs is situation specific (O' Dwyer \& Gilmore, 2013). Based on this, they claimed that the marketing response of independent retail pharmacy is a particular kind of retail SME marketing and as such it is important to review its underlying characteristics to understand its marketing response.

According (O' Dwyer \& Gilmore, 2013), for many SMEs the marketing function is peripheral. However, SME marketing literature identifies the presence of a form of marketing which is unique to small firms, subject to entrepreneurs adapting general marketing concepts for their own purposes while concentrating on incremental innovations (Miles \& Darroch, 2006). In addition, (Deacon and Harris 2013) have noted that there remains a knowledge gap about many of the management actions that small firms take; furthermore they note that debate on the nature of marketing within the small firm and the marketing relationship with entrepreneurship appears to be increasing. (Carson 2010) and (Gilmore 2011) in proposing that SME marketing was in fact entrepreneurial marketing (EM), a distinctive style (characterized by a range of factors that included an inherently informal, simple and haphazard approach), drew attention to the important influence of the entrepreneur/owner/manager in the marketing approach and activities of SMEs.

(Murray et al. 2002) speaks that SME marketing decisions are taken in a haphazard and unstructured manner which leads to spontaneous, reactive and dynamic marketing activities. These decisions are also shaped by the enterprise life cycle as the SME marketing evolves in response to marketing demands, as well as the inherent characteristics and behaviors of the owner and the size of the firm. (Doole et al. 2006) argued that the marketing function in SMEs is hindered by limitations such as poor cash flow, lack of marketing expertise, business size, tactical customer-related problems and strategic customer related problems.

Community pharmacies have traditionally been involved with the successful marketing of products; however, the marketing of a service to patients presents a new challenge for many pharmacists.

In drug retailing, one of the most important sources of added value for customers is represented by the possibility of interaction with trusted pharmacists (Worley-Louis, Schommer, \& Finnegan, 2003). In more recent decades, in fact, pharmacists have moved from a disease-oriented approach to a patient-oriented approach and, by establishing loyal relationships with their customers, have had the opportunity to offer them a tailored and effective service.

(Hepler and Strand 1990) introduced the concept of pharmaceutical care-the therapeutic relationship between pharmacist and patient-as an integral component of patient care. They saw pharmaceutical care as "a covenantal relationship between a patient and a pharmacist in 
which the pharmacist performs drug use control functions (with appropriate knowledge and skill) governed by the awareness of and commitment to the patient's interest." An empathetic and trusting pharmacist-patient relationship is now widely recognized as the cornerstone of pharmaceutical care. Far less appreciated, however, is the importance of the pharmacist-patient relationship in successfully marketing pharmacy-based clinical services. Close collaborative relationships with patients, physicians, and other potential partners are the keys to creating and sustaining demand for pharmacy services on a long-term basis.

Relationship marketing has been defined in various ways. In the narrowest sense, according (Vavra 1992), relationship marketing refers to the use of an organization's database to select preferred customers for a promotional program, such as direct mailing of a special coupon or offering a discount to a limited group of customers. Relationship marketing is defined much more broadly as a practice that encompasses "all marketing activities directed toward establishing, developing, and maintaining successful relationships" (Morgan and Hunt 1994).

The focus of relationship marketing is on developing long term relationships with a targeted group of patients and other partners.

In the pharmacy setting, (Berry 1983) said that relationship marketing refers to attracting, maintaining, and enhancing patient relationships to create mutual benefit for the pharmacist and patient. The most important beneficiary of patient care services is the patient. Given the ongoing nature of chronic drug therapy and the opportunity for repeated interactions between pharmacists and patients, identifying and targeting groups of patients who could benefit from developing long term therapeutic relationships with pharmacists makes sense both professionally and economically.

Such services focus on the relationship with the patient, rather than provision of a material product. Because patients cannot physically see or touch services, (McDonough et al. 1998) claims that they must understand and experience them to derive benefits and appreciate their value.

According (Berry 1983), when a product is marketed, a customer relationship forms from both the seller and buyer are invested in the product. When marketing services, there is a need to form a closer type of relationship with the patient so that both parties buy into the service, creating value in the service. To form this joint buy in from both parties, pharmacists should listen and engage patients during pharmacy visits, identify unmet healthcare needs, and present services during these encounters. Pharmacists should market services using patient friendly language, take time to explain what services are, give patients realistic expectations of the service, and have a plan of how to meet these expectations, (Rovers et al. 1998).

In addition, relationship marketing emphasizes the value of lasting bonds, making this approach well suited to promoting pharmacy services to patients who have chronic conditions and require long-term follow-up to meet their therapeutic goals. Services, which provide a comprehensive review of a patient's medication regimen to identify, prevent, and solve drug therapy problems, usually as a part of an ongoing therapeutic relationship, are a growing area of patient care services. Other services may focus on the management of specific diseases, such as asthma, diabetes, or hypertension, or provide support for health related behaviours, such as smoking cessation or weight loss. Relationship marketing offers a more focused and efficient approach to recruit and retain patients from these populations.

According (Parvativar and Sheth 2000), three core circumstances for building effective relationship marketing in pharmaceutical sector are as follow:

1. One-on-one marketing. Whereas traditional promotional tactics such as running advertisements in newspapers are aimed at a mass market, relationship marketing tactics target selected customers. Using this approach requires the pharmacist to pay greater attention to relationship building and personal selling. Here the first visit of the patient is very important. When a patient initially uses a pharmacy service, it is imperative that he or she has a good experience. The first visit should leave a lasting impression with patients about the benefits of 
pharmacy based care. The patient should be treated in a friendly and professional manner throughout the provision of the service.

2. Retaining patients. Pharmacies often concentrate their promotional efforts on one-time events or services, such as a blood pressure screening day, a month-long diabetes awareness campaign, or a seasonal influenza vaccination program. Although these activities may work well for drawing customers to the pharmacy, they typically offer little incentive for patients to return on a regular basis to take advantage of other, longer-term clinical services. Relationship marketing offers tools to build and sustain relationships with the pharmacy's existing patients. One of them is proper monitoring of the follow up visits of the patients. Follow-up visits allow the pharmacist to assess and monitor the patient's progress, and are an important component of pharmacy-based patient care services that are promoted through relationship marketing. During these visits, pharmacists determine whether the interventions made at prior visits have been effective for addressing the patient's health care concerns and/or drug related problems. Pharmacists should reinforce the importance of progress toward therapeutic goals, praise achievements, and encourage continuation of healthful behaviors. Causes of failure to achieve therapeutic goals also should be carefully investigated. This personal commitment to the existing patients during the follow up visits is important factor for retaining them and a good basis for word of mouth recommendation to others.

3. Taking a longer-term view. Relationship marketing emphasizes developing close and continuing collaborations between an organization (the pharmacy) and its target markets (patients) as well as various stakeholders in patient care (physicians, insurers, and suppliers). Relationship marketing also requires recognizing that relationships take time to grow and mature. Using this approach, the goal of an initial patient encounter should be less to close the sale than to assess the patient's needs and begin to establish the value of pharmacy services.

An essential step for pharmacists adopting relationship marketing is identifying their most promising market segments - the specific groups of patients (and other partners, such as physicians) - that would most likely benefit from a proposed or existing pharmacy-based patient care service, claims (Thomas and Pol 1993). Market segmentation is a focused approach to marketing in which services are offered to a targeted group or groups of patients.

Sometimes a market segment may be attractive but too broad for the pharmacy to serve effectively. In such cases, according (Pulaski 1997), the market segment often can be further divided into market niches, which are more narrowly defined groups of customers. For example, patients who use prescription medications is a large and desirable market segment, but few pharmacies have the staff or resources to offer the full spectrum of services that would meet the needs of this population. However, a pharmacy may successfully fill a niche in this broader market. Examples include providing services to patients with diabetes who use at least two medications to manage their condition, or providing a rapid strep testing service with prescription antibiotic therapy under a collaborative practice protocol (Bennett et al., 2000). By carefully identifying market niches and then developing customized services for those patients, pharmacies stand a better chance of competing even in crowded health care markets.

Once identified, market segments and niches can be profiled to learn more about patients' needs and desires, identify important patient demographic characteristics, and understand patients' reasons for whether or not they participate in a particular program, claims (Sarel and Marmorstein 1996). Based on this knowledge, pharmacists can develop customized marketing strategies for increasing patients' use of a particular service.

Each pharmacy needs to identify its most promising market segments or niches while taking into account internal conditions, including pharmacy staff expertise, interests, and resources, and external market characteristics, such as local patient demographics and unmet health care needs in the community. One of the best tools for identifying attractive market segments is also 
one of the simplest: listening attentively to each patient's comments and feedback. Employing this low-tech strategy can help pharmacists identify and target individual patients as candidates for specific pharmacy services.

When patients make comments, suggestions, or complaints, it is important to listen as closely as possible, paying attention to the person's words and nonverbal cues.

Relationship marketing is cost-effective for the pharmacy because the pharmacy does not have to employ promotional advertisements to attract new patients. By creating loyal patients, the potential for word-of-mouth recommendations increases as well. This cost-saving benefit through relationship marketing can be passed along to the patients by various methods such as decreased fees for service or offering of additional services (Worley and Schommer, 1999).

\section{Marketing Research: Retail Pharmacy Case Study}

\subsection{Problem definition}

Under the auspices of Ministry of Health and the Bureau of drugs and Fund for Health Insurance of RM, it was introduced a low which obligates the pharmacies to work with uniform prices of drugs (reference prices of drugs). That was a legislative measure for which the pharmacists in Macedonia fought in many years before. That measure returned the dignity in the pharmaceutical sector in RM, and stopped the unfair competition that flourished before. This measure puts patients on the first place and fully meets their needs for avoiding the wander for cheap drugs from pharmacy to pharmacy. Today patients have free opportunity to choose from which pharmacy they would buy their medicine because the prices of the drugs are equal in every one. The research process has to be conducted to provide answers about the consumer behavior and consumer buying decision making. The information from the research will help the pharmacy which will be in the focus in the case in making concrete marketing strategy (relationship marketing) for retaining the existing and attracting new consumers when working with uniform prices of drugs.

\subsection{Research design}

Essential technique for gathering data from the respondents used in this case is a survey as quantitative technique for collecting data. The survey was conducted on the patients with wellstructured questionnaire (Appendix 1). The development of the effective questionnaire that will provide valuable data from the respondents is the most important issue which is conducted with special attention in this case. As target population appear the patients of the pharmacy. The sampling frame includes the patients who enter the pharmacy as elements from the whole population. In accordance with the sampling technique, non probability, specifically convenient sampling was used. The sample size contains 250 patients, chosen by convenient sampling and it is important to note that the sample is validated one respondent to answer the questionnaire only once. This means that the sample size from 250 patients is create by 250 different patients. This sample is convenient to provide answers for the purposes of a case study. The results gathered by analyzing small sample size, should be used for particular case and should not be generalized for the whole population. Data collection was conducted through the survey, at the pharmacy. The survey was conducted on daily patients, and as a tool for data collection a well structured questionnaire was used. As supervisors, on the whole survey appears the pharmacists and they appear also as a fieldworkers for collecting the data. The survey was done in two week period and the selected respondents were not more than 20 pay day. This was done to not hinder the daily work of the pharmacy. 
In the pharmacy, a special research corner was improvised with a desk and a box for the completed questionnaires where respondents answer their questionnaires. Respondents, for their goodwill in return were rewarded with small present. The respondents were with complete freedom in answering questions because the employees in the pharmacy were not provided any impact on it. When completed, the questionnaires were left in a specially designed box to preserve the anonymity of the whole research process. The survey guaranteed anonymity for getting honest answers by respondents. At this point it is important to emphasize the positive reactions of the participants from the research. They were surprised by the whole research process and they underlined their sense of personal importance. There were negative reactions, in terms of not having enough time to answer the questionnaires, but the general opinion was that people were pleasantly surprised by the customer care that pharmacy provides.

\subsection{Quantification of the obtained data}

First questions were settled to discover the demographic characteristics of the respondents/patients. From total of 251 respondents who entered the pharmacy, 136 respondents or $55 \%$ were female and 113 or $45 \%$ were male. The distribution of the gender of the patients who entered the pharmacy was almost equal between females and males. With mutual conversation with the pharmacists, the ages of the respondents were divided in 5 subgroups. Age subgroups were developed by the pharmacists and their past experience and observation of the patients in accordance with their age. Offered subgroups are as follow:

- Under 14 years - consumers that cannot visit pharmacies without presence of their parents when buying drugs. They can only buy medical supplements.

- $14-25$ years - individuals who show greater awareness for their health.

- 25 - 45 years - individuals, who are in the peak of their professional and private life. Individuals at this age are the most productive and they express health care for itself and for their family members.

- 45 - 65 years - individuals with stabilized life amplitude, still productive, with preventive action for their health in older age.

- Over 65 years - usually pensioners, with decline life amplitude, and chronic diseases which are coming with the age.

The most of the respondents 97 are respondents between 25 - 45 years of age. Next are those between 45 - 65 years with 65 respondents, followed by 50 respondents aged between 14-25 years. Respondents over 65 years were 35 and expectably the last were individuals under 14 years, only 4 . The age of respondents who entered the pharmacy gave a little bit an unexpected results. Despite the claim of the pharmacists that their most frequent patients are pensioners, the research shows other results. It shows that the most frequent patients are young and middle-aged consumers, especially those aged between $25-45$ years.

The results from the data from the first questions represent a good basis for segment the potential market via demographic characteristics of the respondents. Gender of the respondent's male/female was equal distributed, but the age of the respondents gave valuable results for segment the market over the age. The age subgroups are vulnerable for developing relationship marketing strategy for particular age group. The ages of the respondents are important, because for different age subgroups there are different marketing actions for attracting available.

The question about the residence of living of the respondents shows the importance of the location of the pharmacy. This question discovers is there interdependence or no between the locations of the pharmacy and the residence of living of the respondents. The pharmacy where 
the survey was conducted is located in the city center. The data shows that there is compatibility between the location of the pharmacy and the living residence of the consumers.

Almost half of the respondents 135 are living in the city centre, which is compatible with the micro location of the pharmacy. But the rest of the respondents were living in other location than the city centre, the fact which supports the good micro location of the pharmacy and shows that the potential buyers coming from various living places. The information about the residence of living of potential buyers gives numerous opportunities for managing further marketing activities for attracting the potential buyers with different residence of living.

The data from the next questions represents how often the patients visit pharmacy and how often did they visit particular pharmacy. The results show that the most of the patients usually visit pharmacy and particular pharmacy once or several times per month. The results from these questions it could be connected with the results from the question that follows which discover do the patients always buy from the same pharmacy and if the answer is no to describe what is reason for that. Almost $63 \%$ from the respondents answer that when they enter pharmacy they enter the same pharmacy. This is good information for the pharmacists which support their efforts to retain the existing patients. Results for the reasons why do not respondents usually buy from the same pharmacy are as follow:

Table 1: Buying intention of the respondents in the pharmacy

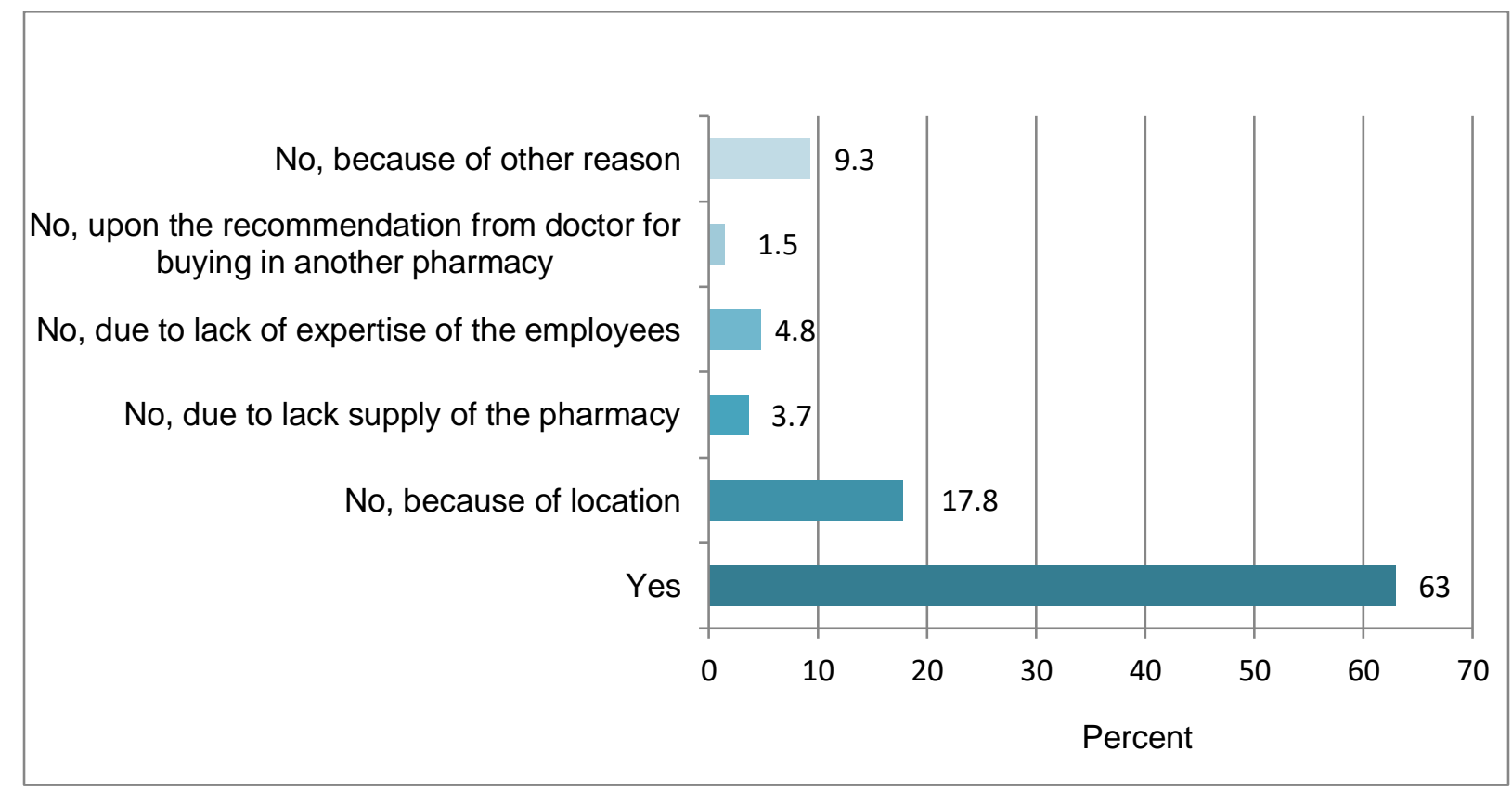

Next data who present the satisfaction/dissatisfaction of the respondents from the service, employees and supply in the pharmacy are presented in the next chart. The respondents had free opportunity to choose between two extremes in the question from completely dissatisfied to extremely satisfy, to describe their level of satisfaction from the service, employees and the supply of the pharmacy. Around $90 \%$ of the respondents said that they are satisfied, very satisfied and extremely satisfied. This fact shows that respondents are generally satisfied with 
this three constituent factors, service, employees, supply, which makes one pharmacy to be successful in retaining the existing patients.

Table 2: Rating scale for consumer's satisfaction

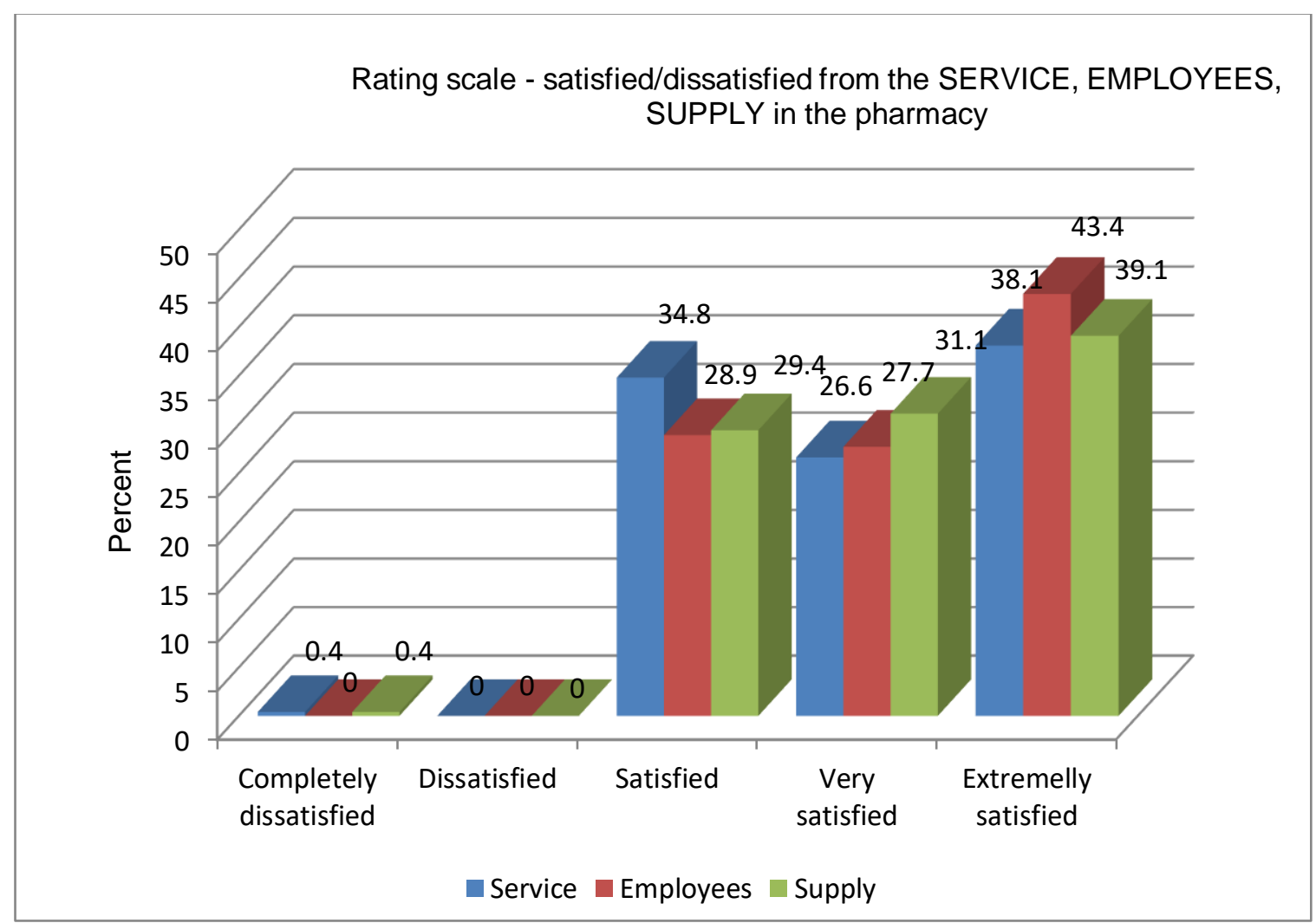

The data how the personal commitment and the consultative role of the pharmacists are important/unimportant to the patients are as follows. Near $57 \%$ of the respondents said that these aspects are extremely important and $32 \%$ of the respondents respond that personal commitment of the pharmacists and their consultative role is very important to them. From this data is reflected the fact that employees and the service they provide to the patients in form of their personal commitment and consultative role toward them is very important for the pharmacies in retaining the existing consumers and building long-life relationship. These aspects are very important in providing consumer care to the existing patients and could serve as a good reference for attracting new ones.

The data produced from the next two questions, are to discover how patients react when they buy strictly medicines. From the working practice of the pharmacies there is situation when the medicine with same medical structure and same medical purpose is offered by different manufacturers under different name and prices. The results are as follow. Almost $65 \%$ of the respondents answer that they buying medicines under the recommendation of the pharmacists when they have to choose between the same drugs offered from different manufacturers. This statement once more supports the importance of the pharmacist and their personal commitment they provide to the patients. Significantly $21 \%$ of the respondents answer that they have favorite manufacturer and buy according to the manufacturer. 
The last question discovers the intention of the consumers to recommend the concrete pharmacy to others. General statement is that the existing patients are willing to recommend the pharmacy to others. This statement is important for the pharmacy and gives opportunity by providing consumer care to the existing consumers to attract new ones under the recommendation on them from the existing (word-of-mouth marketing).

Table 3: Willingness for a recommendation the pharmacy to other patients

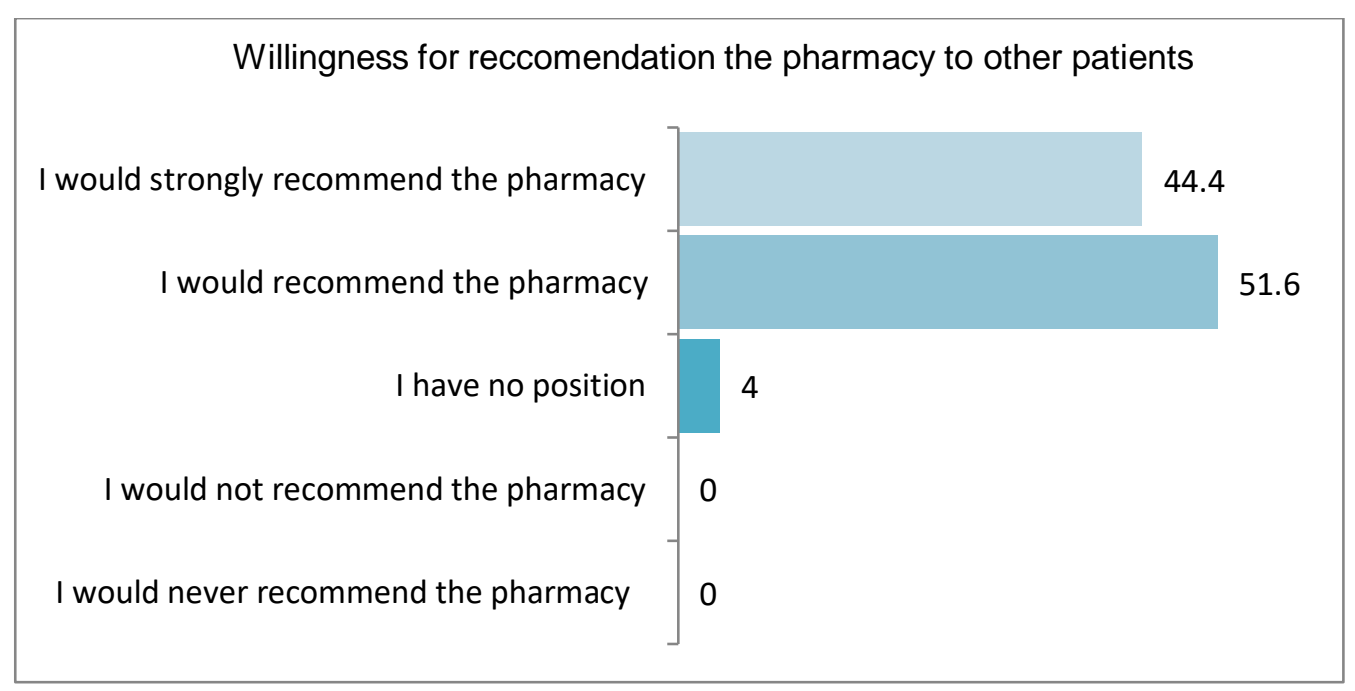

\section{Conclusion and recommendations}

Analyzed data discovers the patients' demographic characteristics. The respondents who enter the pharmacy were mainly middle aged, followed of young and older patients. Gender of the patients was equal distributed by females and males. The main purpose to enter the pharmacy was their chronic or current disease. The psychological dimension of the patients' behavior is recognized with the fact that the core motive to enter the pharmacy is their disease. They percept the pharmacies as places where they can by firstly medicines, more than any other products except drugs which one pharmacy includes. For increasing the profits, the marketing efforts of the pharmacy should be driven to present itself that it is a place where the patient should buy other range of products than medicines, only. Second psychological characteristic of the patients comes from the fact that they note the personal commitment and consultative role of the pharmacists as very important to them. Patients emphasize the fact that they are to build long life relationship with the pharmacy from which they buying. So, the marketing efforts in this regard, should be driven to provide customer loyalty by developing loyalty programs such as frequency programs, club membership programs or database marketing. The buying decision process of the patients especially when they are buying drugs is simple to be described, than the buying decision process when consumer buying something else. It starts when the patients recognizes problem (need) usually in form of some disease. After visiting the doctor specialist, then they enter pharmacy and with the consultation with the pharmacist choose between the available medicines intended to cure particular disease. Their purchase decision should be 
reached between same structured medicines in composition, but manufactured by different manufacturer under different name and different price.

Post purchase behavior is perceived by the fact if the patient is cured from the disease and from their satisfaction from the consultative role of the pharmacists for the current disease.

The need to buy medication is understandable by itself, but to encourage a reaction or to discover the trigger which drives the patients to buy something else from the pharmacy would be a challenging situation for the pharmacy. The marketing efforts should be set to highlight the preventive action in order to secure health life. The pharmacy must to include various marketing stimuli to inform the patients that there are varieties of products in the health care sphere that are not called medicines. The buying behavior on the patients toward pharmacies should be changed by incentive to buy various medical supplements, devices, cosmetic products, childcare products, etc., as products which directly secure preventive action and provide the health care. The personal and psychological characteristics of the patients as well as their buying decision process toward the pharmacy represent a good basis to offer various marketing actions that can provide greater profits for the pharmacy in the future.

At the beginning it has to be mentioned the fact that the pharmaceutical marketing itself is complex concept where the ethics should be taken in consideration. The manufacturers of the drugs has own marketing departments which create the global marketing strategy for a drug toward the patients. The pharmacies as retail stores of the big drug manufactures are directly influenced by the marketing strategy for a drug provided by the manufacturer. In this manner the marketing actions of the pharmacies are limited.

As is widely described in Chapter 2, the marketing efforts for the independent retail pharmacies like the pharmacy which is in the focus in this case should be translated in practice by building long-life relationship with the existing patients. These relations should be based on mutual confidence between the pharmacists and the patients. Here the role of the pharmacist should be underlined in delivering personal commitment on each patient separately. The results from the research questionnaire, especially those ones intended to discover particularly the importance of the relation pharmacist/patient and its mutual trustiness, support the fact of the importance of their relations. The satisfaction of the existing patients from the service they receive in the pharmacy, will serve as good recommendation from them for acquiring new ones. In building consumer care and long-life relationship with the patients there are few actions available. Club membership and frequency programs are designed to provide rewards to customers who buy frequently and in substantial amounts. The companies offer club membership cards to the consumers and usually the reward is in from of some discount of the value on the next purchase. The last recommendation for the pharmacy, having in mind the world practice, is the idea to create own pharmaceutical bulletin on unprofitable basis. It will be sponsored by the pharmacy, will be distributed among the patients once monthly, and will include topics about the health care. The main function of the pharmaceutical bulletin will be informative: to aware patients with the products available for supporting their health, to provide patients with actual topics for the health care according to the world practice, and finally will serve for advertising of the pharmacy. The production of the own pharmaceutical bulletin is one of the tool of the relationship marketing.

Advertising actions of the pharmacies should be translated in practice if they promote itself that they are places where the patients can buy various products in health care different from medicines. Having in mind the personal and psychological characteristics of the patients there will be a good basis to segment the potential market and develop direct marketing actions to different target groups. The marketing actions should be implemented in practice by advertising on Social Networks or the local electronic mediums. Especially interesting are social media which have a big databases of potential consumers already segmented in target groups by computer software. For a small amount they provide possibilities for focused marketing in front 
of the potential target group of consumers (young, older, male, female, specific region, pregnant women's etc.).

References

Bennett M.A., Blank D., Bopp J. (2000): Strategies to improve compensation for pharmacybased patient care services. Journal American Pharmacy Association,40, 747-55.

Berry L. (1983): Relationship marketing. In: Berry L., Shostack G.L., Upah G.D., eds. Emerging Perspectives on Services Marketing. Chicago, IL: American Marketing Association,25-8.

Carson D. (2010): Interface research: a commentary on a commentary- ten years on. Journal of Research in Marketing and Entrepreneurship, 12(1), pp. 8-10.

Deacon J. H. \& Harris J. (2013): Contextual Marketing. In: P. Harrigan, R. Jones \& Z. Sethna, eds. Entrepreneurial Marketing: Global Perspectives. Bingley: Emerald Publishing, pp. 45-59.

Desselle S.P. \& Zgarrick D.P. (2005): Pharmacy Management: essentials for all practice settings. New York: McGraw Hill

Doole, I., Grimes, T. \& Demack, S., (2006): An exploration of the management practices and processes most closely associated with high levels of export capability in SMEs, Marketing Intelligence and Planning, 24(6), pp. 632-647.

Drucker P. (1973): Management: Tasks, Responsibilities, Practices, New York: Harper and Row, p.64-5

Gummesson E. (2007): Exit services marketing: enter service marketing, Journal of Consumer Behavior, 6(2), p.113-41

Hepler C.D., Strand L.M. (1990): Opportunities and responsibilities in pharmaceutical care. Am J Hosp Pharm.,47, 533-43.

Kayne S., Pharmacy Business Management. London: Pharmaceutical Press, 2005

Kotler P., Keller K.L., Brady M., Goodman M. and Hansen T. (2009): Marketing Management, Harlow, England, Pearson Education Limited/Prentice Hall, p.25

Levinson J. C. (2007): Guerilla Marketing: Easy and Inexpensive Strategies for Making big Profits from Your Small Business, $4^{\text {th }}$ edn, Boston, MA: Houghton Mifflin

McCarthy E. J. and Perreault W. D. (2002): Basic Marketing: A Global-Managerial Approach, $14^{\text {th }}$ edn, Homewood, IL: McGraw-Hill/Irwin

McDonough R.P., Pithan E.S., Doucette W.R. (1998): Marketing pharmaceutical care services. $J$ Am Pharm Assoc., 38, 667-80.

Miles M. \& Darroch J. (2006): Large firms, entrepreneurial marketing processes, and the cycle of competitive advantage. European Journal of Marketing, 40(5/6), pp. 485-501. 
Morgan R.M., Hunt S.D., (1994): The commitment-trust theory of relationship marketing, Journal of Marketing, 58, 20-38.

Murray J., O'Driscoll A. \& Torres, A. (2002): Discovering diversity in marketing practice. European Journal of Marketing, 36(3), pp. 373-390.

O' Dwyer M. \& Gilmore A. (2013): Innovative Marketing in SMEs: An "APT" Conceptualization. In: P. Harrigan, R. Jones \& Z. Sethna, eds. Entrepreneurial Marketing: Global perspectives. Bingley: Emerald Publishing, pp. 179-199.

Parvatiyar A., Sheth J.N. (2000): The domain and conceptual foundations of relationship marketing. In: Sheth JN, Parvatiyar A, eds. Handbook of Relationship Marketing. Thousand Oaks, CA: Sage Publications; 3-38.

Pulaski J.M. (1997): An emerging niche market opportunity, Med Group Manage Journal, 69-74.

Rovers J.P., Currie J.D., Hagel H.P. (1998): A Practical Guide to Pharmaceutical Care. Washington, DC: American Pharmaceutical Association; 1998.

Sarel D., Marmorstein H. (1996): Identifying new patient prospects: efficacy of usage segmentation, Journal of Health Care Marketing,16, 38-43.

Thomas R.K., Pol L.G. (1993):Health demography comes of age, Health Marketing Journal, 10, 67-82.

Vavra T.G., (1992): After marketing: How to Keep Customers for Life through Relationship Marketing. Homewood, IL: Business One-Irwin; 1992

Worley M.M., Schommer J.C. (1999): Pharmacist-patient relationships: factors influencing quality and commitment, Journal of Society Pharmacy.16, 157-73.

Worley-Louis, M., Schommer, J.C., \& Finnegan, J.R. (2003): Construct identification and measure development for investigating pharmacist-patient relationship. Patient Education and Counseling, 51(3), 229-238. 


\section{Appendix 1}

\section{RESEARCH QUESTIONNAIRE}

Introductory note: The questionnaire is anonymous and your honesty in answering the questions would contribute to the quality and accuracy of research! The survey is conducted for scientific purposes and the results from the research will be transparent displayed! Completing the survey should take no more than $5 \mathrm{~min}$ ! If you have anything unclear about the questionnaire, please consult your supervisor!

1. Gender (circle)
a) Male
b) Female

2. Age
a) Under 14 years.
b) from 14-25 years.
c) from $25-45$ years.
d) from 45-65 years.
e) Over 65 years.

3. Residence of living
a) Center
b) Other settlement in Stip
c) Surrounding village
d) Other town

4. How often do you visit a pharmacy? (Mark with X)
once per week
$\square$ several times per week
$\square$ once per month
$\square$ several times per month
$\square$ several times per year 
5. How often do you visit the concrete pharmacy
once or several times per week
once or several times per month
once or several times per year
I visit for the first time

6. What is your most common reason for visiting pharmacy (multiple choice)

$\square$ Chronic disease

$\square$ Current disease

$\square$ Consultation with a pharmacists

$\square$ Preventive aaction in acordance with potential disease

$\square$ Purchase of medical devices

$\square$ Purchase of other medical products

7. Do you always buy from this pharmacy, and if your answer is NO, please note the reason why? (multiple choice)

a) Yes

б) No, because,

$\square$ of location

$\square$ of the poor supply of the pharmacy

$\square$ of lack of expertise of the staff

$\square$ of recommendation from doctor to buy in other pharmacy

$\square$ of other reasons

\begin{tabular}{|l|c|c|c|c|c|}
\hline & $\begin{array}{c}\text { Completely } \\
\text { dissatisfied }\end{array}$ & Dissatisfied & Satisfied & Very satisfied & $\begin{array}{c}\text { Extremely } \\
\text { satisfied }\end{array}$ \\
\hline Service & 0 & 0 & 0 & 0 & 0 \\
\hline Employees & 0 & 0 & 0 & 0 & 0 \\
\hline
\end{tabular}




\begin{tabular}{|l|l|l|l|l|l|} 
Supply & 0 & 0 & 0 & 0 & 0 \\
\hline
\end{tabular}

8. Rating scale for your satisfaction in the pharmacy from:

9. How important for you is the consultative role and the personal commitment provided from the pharmacists in this pharmacy?

\begin{tabular}{|c|c|c|c|c|}
\hline $\begin{array}{c}\text { Extremely } \\
\text { important }\end{array}$ & Very important & $\begin{array}{c}\text { Sometimes } \\
\text { important }\end{array}$ & $\begin{array}{c}\text { Not very } \\
\text { important }\end{array}$ & $\begin{array}{c}\text { Completely } \\
\text { unimportant }\end{array}$ \\
\hline $\mathrm{O}$ & $\mathrm{O}$ & $\mathrm{O}$ & $\mathrm{O}$ & $\mathrm{O}$ \\
\hline
\end{tabular}

10. When you enter the pharmacy, except drugs, what else you usually buy?

$\square$ medical supplements (nutritional products, vitamins, natural products, etc.)

$\square$ medical devices (devices for measuring blood preasure and sugar in blood, stethoscopes, gauzes, bandages, syringes, etc.)

$\square$ cosmetics products (various creams and milks for body and face, shampoos, soaps, toothpastes, toothbrushes, etc.)

children products (soothers, bottles, toys, strollers for children, etc.)

11. Would you recommend this pharmacy on other patients?

\begin{tabular}{|c|c|c|c|c|}
\hline $\begin{array}{c}\text { I would never } \\
\text { recommend the } \\
\text { pharmacy }\end{array}$ & $\begin{array}{c}\text { I would not } \\
\text { recommend the } \\
\text { pharmacy }\end{array}$ & $\begin{array}{c}\text { I have no } \\
\text { position }\end{array}$ & $\begin{array}{c}\text { I would } \\
\text { recommend the } \\
\text { pharmacy }\end{array}$ & $\begin{array}{c}\text { I would strongly } \\
\text { recommend the } \\
\text { pharmacy }\end{array}$ \\
\hline 0 & 0 & 0 & 0 & 0 \\
\hline
\end{tabular}

12. If you have additional proposals, suggestions or ideas for improving our performance, please write freely in the following lines:

Thank you for your attention!!! 